\title{
Prescription of Drugs to be Administered through Feeding Tubes in a Brazilian Hospital: Profile and Qualification
}

\author{
Adriana Rosemary Presoti ${ }^{1}$, Mariana Martins Gonzaga do Nascimento ${ }^{2 *}$ and Luciene Alves Moreira Marques ${ }^{3}$ \\ ${ }^{1}$ Centro Barbacenense Hospital of Medical and Social Assistance, Brazil \\ ${ }^{2}$ René Rachou Research Center, Oswaldo Cruz Foundation, Brazil \\ ${ }^{3}$ Faculty of Pharmaceutical Sciences, Federal University of Alfenas, Brazil
}

\begin{abstract}
The objective of this study was to trace the profile of solid pharmaceutical forms prescription via feeding tubes in a hospital, and elaborate a table with data that may support the qualification of prescription and administration of drugs through feeding tubes. Through a retrospective analysis of patients' prescription, 43 different solid dosage forms drugs administered through feeding tubes were listed. Moreover, it was found that an average of $3.3 \pm 1.2$ drugs was prescribed to be administered through this via per day per patient. Thirteen out of the 43 prescribed drugs had restrictions regarding their administration through feeding tubes. It was found that $86.7 \%$ of patients used at least one drug that could interact with enteral nutrition during the time that they remained hospitalized. This study allowed the diagnosis of a concerning cenario, where the quality of the patients' pharmacotherapy may be impaired by the possible occurrence of drug-nutrient interaction.
\end{abstract}

Keywords: Enteral nutrition; Drug; Pharmaceutical preparations; Drug interaction; Pharmacy service; Hospital

\section{Introduction}

When patients are unable to be fed orally, enteral or parenteral nutrition is recommended [1-3]. Enteral Nutrition (EN) offers some advantages over parenteral nutrition as the decrease in hospitalization time, reduced clinical complications, greater convenience, improvement in bowel function, maintenance of the structure and function of the gastrointestinal mucosa, and less possibility of bacteria translocation $[2,4,5]$. Furthermore, the placement of a feeding tube in the gastrointestinal tract opens the possibility of drug delivery through this via, also reducing the risk of administration of injectable dosage forms [6,7]. However, before implementing an adequate pharmacotherapy via feeding tubes, one must evaluate some important points such as the diameter and length of the tube, its location in the gastrointestinal tract, the site of action and absorption of the drug, EN administration period, drug-nutrient interactions, drug compatibility with the administration technique, and the physiological and pathological factors inherent of the patient, which makes this practice quite complex [2,4-6,8].

Another inconvenience of drug administration via feeding tubes is that most of them are not in liquid dosage forms and, therefore, techniques of dispersion and grinding are required [2,9-11]. The method of dispersion of solid pharmaceutical forms is the most suitable for the administration of solid drugs through this via because it offers the patient the total dose of the drug prescribed. On the other hand, during the grinding method losses on the pharmaceutical contents can occur through the suspension of particles in the air or adherence on the utensils used during the process [2]. However, both techniques alter the technology and pharmacokinetics of the drug, generating the need for knowledge of their properties and the most appropriate technique for their administration [2,12-16].

Guidelines for the preparation and administration of medications via enteral probe are easily found in the literature [15]. Nevertheless, according to the American Society for Parenteral and Enteral Nutrition 6 , the daily practice tends to differ a lot from general guidelines, which can interfere with the success of pharmacotherapy. The use of inappropriate techniques not only jeopardize the safety and efficacy of therapy, but may also cause obstruction of the probe, resulting in patient discomfort, increased costs and longer time spent by nursing staff with feeding tube handling [6,9,10,17-19].

In view of this, it is important to determine the profile of drugs prescription in solid dosage form for administration via feeding tubes and to develop tools that can support the qualification of the prescription and administration of these kinds of drugs, mitigating the adverse events caused by this practice.

\section{Methods}

A descriptive, observational and retrospective study was conducted in a medium-sized philanthropic hospital (115 beds), specialized in cardiology and oncology, located in the city of Barbacena, Minas Gerais state, Brazil.

Amongst the universe of prescriptions sent to the pharmacy sector in the period within January 1 to March 31, 2010, there had been selected those belonging to patients who received enteral nutrition via feeding tube for 48 hours or more. There have been identified and listed all solid dosage form drugs prescribed to be administered through enteral feeding.

A list with every solid dosage form drug used on the institution was generated from the pharmacy's management system. Information on the most appropriate technique for administration of each drug via feeding tubes and their compatibility with grinding/dispersion were obtained through an electronic search in the PubMed database with the following keywords: "enteral feeding", "drug-nutrient interaction.

*Corresponding author: Nascimento MMG, René Rachou Research Center, Oswaldo Cruz foundation, Alameda dos Jacarandás, 481 - Bairro São Luiz, 31275-060 - Belo Horizonte-MG, Brazil, Tel: (5531)84845513; E-mail: marianamgn@yahoo.com.br

Received May 01, 2013; Accepted July 04, 2013; Published July 08, 2013

Citation: Presoti AR, Gonzaga do Nascimento MM, Moreira Marques LA (2013) Prescription of Drugs to be Administered through Feeding Tubes in a Brazilian Hospital: Profile and Qualification. J Gen Pract 1: 112. doi: 10.4172/2329-9126.1000112

Copyright: (C) 2013 Presoti AR, et al. This is an open-access article distributed under the terms of the Creative Commons Attribution License, which permits unrestricted use, distribution, and reproduction in any medium, provided the original author and source are credited. 
Further studies were gathered after the analysis of the references cited in the scientific articles retrieved with the keywords above. A consultation to the individual monograph of each drug was also carried out in the Micromedex [20] database focusing on information about drugnutrient interaction, incompatibilities or specific recommendations for drug administration through feeding tubes.

The study was approved by the Ethics Committee of Universidade Estadual de Montes Claros (UNIMONTES) and by the direction of the institution in which it was accomplished.

\section{Results}

A total of 611 prescriptions were selected. From those, 54 prescriptions from 13 patients were excluded because either NE was used for less than 48 hours or they did not use any solid dosage form. Through the analysis of the remaining 557 prescriptions from 45 patients ( 21 men and 24 women) with average age of $70.4 \pm 15.5$, there were identified and listed 43 different solid dosage form drugs. The average number of drugs in solid dosage form administered per patient per day was equal to $3.3 \pm 1.2$, ranging between 1 and 14 .

By consulting the monograph of drugs identified in the database Micromedex (2009), it was found that only 5 of the 43 drugs prescribed (11.6\%) presented information regarding its administration via probes (Table 1).

Through the electronic search, 33 articles were identified, of which 17 were excluded after reading the title, and one for its summary. From the analysis of reference lists of the retrieved articles, twenty new pieces were recovered and analyzed.

Among the standard drugs in the institution, there have been identified 100 drugs in solid dosage form for oral use. Such drugs were placed on a table with its generic name, dosage form, exchange options in the institution, and recommendations for its administration via feeding tubes drawn from scientific articles and the Micromedex database. This table was presented to the medical and nursing staff and made available for consultation in prescription and drug preparation rooms. Of the 100 drugs in solid dosage form of the institution, 35 presented restrictions on their administration via feeding tubes.

Based on the data table built with all solid dosage forms for oral use of the institution, a re-examination of the prescriptions analyzed in the first phase of this study showed that, thirteen out of the 43 drugs prescribed, $(30.2 \%)$ had restrictions on their administration via feeding tubes (Table 1)

It was also detected that $86.7 \%$ of the patients used at least one drug that presents a risk of interaction with enteral nutrition during the time that they remained hospitalized. On average, 1.2 drugs with potential for interaction with enteral nutrition were prescribed per day, per patient.

\section{Discussion}

In this study, it was found that, as described in the literature, the solid dosage form of medication is often administered via probe in patients on enteral nutritional support [11,21].

The average number of drugs in solid dosage form prescribed by patient in a study conducted by Heineck et al. [21] was $5 \pm 4.0$ and $5.6 \pm$ 2.2 in a study in another Brazilian Study, higher than the average found in this study $(3.3 \pm 1.2)[21,22]$. This may be related to the clinical profile of the institution, since some patients whose prescriptions were analyzed are submitted to cancer treatment and receive few oral drugs. This profile could also explain the range detected in the number of

\begin{tabular}{|c|c|c|c|}
\hline Drug & Dosage Form & Relevant recommendations and information & Frequency of prescription \\
\hline Captopril & Tablet & $\begin{array}{l}\text { Concomitant administration with enteral nutrition may reduce its absorption. Monitor blood } \\
\text { pressure [23]. }\end{array}$ & 70 \\
\hline Ciprofloxacin & Coated tablet & $\begin{array}{l}\text { Concomitant administration with enteral nutrition (EN) may reduce its absorption. It is } \\
\text { recommended to stop the EN one hour before and two hours after administration. Replace } \\
\text { ciprofloxacin with another quinolone or use the injectable solution }[1,2,10,12,14,16,18,23] \text {. }\end{array}$ & 2 \\
\hline Digoxin* & Tablet & $\begin{array}{l}\text { Concomitant administration with enteral nutrition (EN) may reduce its absorption, especially if } \\
\text { it is rich in fiber. It is recommended to monitor serum concentrations of the drug }[18,20,21,23] \text {. }\end{array}$ & 29 \\
\hline Phenytoin* & Tablet & $\begin{array}{l}\text { Concomitant administration with enteral nutrition }(\mathrm{EN}) \text { may reduce its absorption. It is } \\
\text { recommended to monitor serum concentrations of drug and/or stop the EN one hour before } \\
\text { and two hours after administration }[1-4,9,10,12,14,16,18,20,21,23] \text {. }\end{array}$ & 84 \\
\hline Haloperidol & Oral Solution & $\begin{array}{l}\text { Concomitant administration with enteral nutrition (EN) may cause precipitation of NE due to } \\
\text { the acidic } \mathrm{pH} \text { of the solution. It is recommended to stop the EN one hour before and two hours } \\
\text { after administration }[4,23]\end{array}$ & 3 \\
\hline Hydralazine* & Tablet & $\begin{array}{l}\text { Concomitant administration with enteral nutrition (EN) may reduce its absorption. It is } \\
\text { recommended to stop the EN one hour before and two hours after administration. Monitor } \\
\text { blood pressure }[20,23] \text {. }\end{array}$ & 72 \\
\hline Isosorbide & Sublingual tablet & It can not be crushed $[1,2,12,16]$. & 96 \\
\hline Levothyroxine* $^{*}$ & Tablet & $\begin{array}{l}\text { After crushing the tablet, disperse in water and protect the solution from light. Concomitant } \\
\text { administration with enteral nutrition }(\mathrm{EN}) \text { may reduce its absorption, especially if it is rich in } \\
\text { fiber. It is recommended to stop the NE one hour before and two hours after administration. } \\
\text { Monitor serum concentrations of the drug }[16,20,23] \text {. }\end{array}$ & 98 \\
\hline Methyldopa & Coated tablet & $\begin{array}{l}\text { Concomitant administration with enteral nutrition (EN) may reduce its absorption. It is } \\
\text { recommended to stop the EN one hour before and two hours after administration. Monitor } \\
\text { blood pressure [23]. }\end{array}$ & 79 \\
\hline Metoprolol & Controlled release tablet & It cannot be crushed. Risk of drug-dumping $[1,6,10-12,19,23]$. & 16 \\
\hline Nifedipine & Controlled release tablet & Cannot be crushed. Risk of drug-dumping $[1,6,9-12,16,19]$. & 8 \\
\hline Omeprazole* & Capsule & $\begin{array}{l}\text { Do not crush: enteric-coated granules. Risk of inactivation of the drug in gastric } \mathrm{pH} \text { [1- } \\
\qquad 4,6,12,16,20]\end{array}$ & 20 \\
\hline Propatilnitrate & Sublingual tablet & It cannot be crushed $[1,2,16]$. & 10 \\
\hline
\end{tabular}

* Solid dosage form drugs that presented relevant recommendations and information regarding their administration via feeding tubes according to Micromedex (2009).

Table 1: Non-crushable drugs and drugs that interact with enteral nutrition. 
Citation: Presoti AR, Gonzaga do Nascimento MM, Moreira Marques LA (2013) Prescription of Drugs to be Administered through Feeding Tubes in a Brazilian Hospital: Profile and Qualification. J Gen Pract 1: 112. doi: 10.4172/2329-9126.1000112

drugs in solid dosage form that each patient received (ranging from 1 to 14). In future studies, it is believed that it would be productive to section the population studied according to the clinical characteristics [23].

During the stage of literature research in the database Micromedex, only five of the 43 monographs of drugs analyzed presented information regarding limitations for the administration of medication via feeding tubes. However, according to scientific papers retrieved in this study, other eight drugs could also present such limitations. It is believed therefore that the Micromedex database should not be used as the only source of information in this type of analysis, being necessary the complementation with other research sources, especially secondary.

It was detected that complete and specific literature related to the administration of drugs via feeding tubes is lacking. The compilation of a table with such information was an alternative contemplated in this study, and it is believed that, besides serving as a source of information for professionals in the institution, it may support the transmission of pharmaceutical interventions and suggestions to the multidisciplinary healthcare team in order to qualify the prescription and administration of drugs via enteral probes. However, it should be emphasized the importance of periodic update on that instrument.

During the prescription analysis, the amount of times that some drugs that are critical to the administration via feeding tubes were prescribed, draw special attention: captopril (prescribed for thirteen patients), hydralazine (ten patients), levothyroxine and omeprazole (eight patients each). These data are worrisome because they can undermine the effectiveness of the patients' pharmacotherapy. It is also concerning the fact that a total of 24 patients had controlled release tablets (Metoprolol to 16 patients and nifedipino to 8 patients) prescribed to be administered via probe. This practice is very problematic since it can expose the patient to immediate drug dumping, cause severe reduction in blood pressure and even lead them into a fatal cardiac arrest [6]. Given this and considering the complexity of the drug and nutritional hospital therapy, it is recommended that pharmacists work with multidisciplinary teams of nutritional therapy seeking qualification of the overall treatment of patients and the minimization of errors in drug administration via feeding tubes $[4,5]$.

\section{References}

1. Sacks GS (2008) Drug-nutrient considerations in patients receiving parenteral and enteral nutrition. Pract Gastroenterol 28: 39-48.

2. Williams NT (2008) Medication administration through enteral feeding tubes. Am J Health Syst Pharm 65: 2347-2357.

3. Schweigert ID, Pletsch UM, Dallepiane LB (2008) Interação medicamentonutriente na prática clínica. Rev Bras Nutr Clin 23: 72-77.

4. Gago Sánchez Al, Garzas Martín de Almagro C, Cárdenas Aranzana M, Calañas Continente A, Calleja Hernández MA (2006) Pharmaceutical care for patients with enteral nutrition. Farm Hosp 30: 44-48.

5. Matsuba CS, De Gutiérrez MG, Whitaker IY (2007) Development and evaluation of standardized protocol to prevent nasoenteral tube obstruction in cardiac patients requiring enteral nutrition with restricted fluid volumes. J Clin Nurs 16: 1872-1877.

6. Bankhead R, Boullata J, Brantley S, Corkins M, Guenter P, et al. (2009) Entera nutrition practice recommendations. JPEN J Parenter Enteral Nutr 33: 122-167.
7. Luft VC, Vieira DM, Beghetto MG, Polanczyk CA, Mello ED (2008) Suprimento de micronutrientes, adequação energética e progressão da dieta enteral em adultos hospitalizados. Rev Nutr 21: 513-523.

8. Stroud M, Duncan H, Nightingale J; British Society of Gastroenterology (2003) Guidelines for enteral feeding in adult hospital patients. Gut 52: vii1-1vii12.

9. Izco N, Creus N, Massó J, Codina C, Ribas J (2001) Incompatibilidades fármaco-nutrición enteral: recomendaciones generales para su prevención. Farm Hosp 25: 13-24.

10. Boullata $\mathrm{Jl}$ (2009) Drug administration through an enteral feeding tube. Am J Nurs 109: 34-42.

11. van den Bemt PM, Cusell MB, Overbeeke PW, Trommelen M, van Dooren $D$, et al. (2006) Quality improvement of oral medication administration in patients with enteral feeding tubes. Qual Saf Health Care 15: 44-47.

12. Beckwith MB, Feddema SS, Barton RG (2004) A guide to drug therapy in patientes with enteral feeding tubes: dosage form selection and administration methods. Hosp Pharm 39: 225-237.

13. Brown RO, Dickerson RN (1999) Drug-nutrient interactions. Am J Manag Care 5: 345-352.

14. Chan LN (2002) Drug-nutrient interaction in clinical nutrition. Curr Opin Clin Nutr Metab Care 5: 327-332.

15. Heydrich J, Heineck I, Bueno D (2009) Observation of preparation and administration of drugs by nursing assistants in patients with enteral feeding tube. Rev Bras Ciênc Farm 45: 117-120.

16. Lima G, Negrini NMM (2009) Assistência farmacêutica na administração de medicamentos via sonda: escolha da forma farmacêutica adequada. Einstein São Paulo 7: 9-17.

17. Moura MRL, Reyes FGR (2002) Interação fármaco-nutriente: uma revisão. Rev Nutr 15: 223-238.

18. Gregory C (2006) Drug and enteral feed interactions. J Hum Nutr Diet 19: 237-239.

19. Martins Gonzaga do Nascimento M, Max Moreira Reis A, Yeznach Wick J, Queiroz Ribeiro A (2012) Drug administration through feeding tubes; an integrated qualification program. Nutr Hosp 27: 1309-1313.

20. Micromedex (2010). Healthcare Series.

21. Heineck I, Bueno D, Heydrich J (2009) Study on the use of drugs in patients with enteral feeding tubes. Pharm World Sci 31: 145-148.

22. Gorzoni ML, Della Torre A, Pires SL (2010) Drugs and feeding tubes. Rev Assoc Med Bras 56: 17-21

23. Piñeiro Corrales G, Olivera Fernández R, Guindel Jiménez C; Grupo de Nutrición SEFH/SENPE (2006) Drug administration in patients with enteral tube nutrition. Nutr Hosp 21: 1-216. 